\title{
La Industria Mediática en el Escenario Mundial
}

\author{
Maricruz Castro Ricalde \\ Instituto Tecnológico de Estudios Superiores de Monterrey, \\ campus Toluca
}

El orden natural con que se presentan los hechos necesitan el distanciamiento que brinda la mirada histórica para extraer de ellos una lógica, una coherencia que permita la posesión de una visión global sistemática e integrada. Este es el propósito de Armand Mattelart en uno de sus últimos libros: La comunicación- mundo. Historia de las ideas y de las estrategias. Fruto de una investigación, cuyos embriones podemos encontrar en varias de sus obras anteriores, este texto ambiciona ordenar el paisaje de la comunicación internacional. El resultado es un utilísimo fresco que ofrece una genealogía del tema, pero sobre todo lo contextualiza. Así, éste no es simplemente un libro de historia de la comunicación internacional, mas bien es una obra que ofrece los elementos suficientes para analizar cuestiones como la política y la industria mediática en su interrelación con el escenario mundial; el mito de la globalización, su impacto en los medios y como, al mismo tiempo, éstos han influido dentro del imaginario social; la idea que la comunicación es la panacea que redimirá a la sociedad, entre otras.

Nuestra intención es ofrecer un panorama de las cuestiones que Mattelart aborda en dicho texto, a partir de los grandes núcleos sobre los que hace girar la obra: la guerra, el progreso y la cultura. Para ello, aprovecharemos otros textos del autor, en los que desarrolla fragmentaria, colateral o complementariamente material relativo al tema.

\section{Primeros escenarios}

En las últimas décadas del siglo pasado, la comunicación fue vista como "agente de la civilización". Las dimensiones del mundo cambian tajantemente con los enormes tendidos de las redes ferroviarias, el surgimiento del telégrafo inalámbrico, la comunicación interoceánica, a través del cable submarino, la navegación, entre otros factores. La idea de inaccesibilidad espacial es reemplazada por la de interdependencia. Pasarán todavía algunos años antes de que se evaluara que éste no sólo era un problema de distancia geográfica, sino de una naturaleza mucho más compleja como la interculturalidad y los modos de sociabilización de cada grupo humano. 
No obstante, las redes ferroviarias, telegráficas y postales nutrirán lo que Mattelart llama la "ideología redentora de la comunicación”. Frases como "Todos los hombres serán hermanos" podían verse en las exposiciones universales del siglo XIX. La comunicación era considerada como la plataforma de una tendencia universal y pacifista. Sin embargo, acercándonos más a los hechos de la época, podemos percibir como el discurso de algunos países se distanciaba de sus verdaderos intereses, por una parte, y cómo la influencia de los medios de comunicación podía contribuir a determinar tanto a la opinión pública como a las figuras con un poder real de decisión sobre los acontecimientos internacionales.

Así, a fines del siglo pasado, los Marines del ejército de los Estados Unidos de América desembarcarán en Cuba, en 1898, con la excusa de ayudar a sus habitantes a liberarse de la égida española. Éste será el escenario ideal para que la prensa sensacionalista de Randolph Hearst demuestre su capacidad para generar acontecimientos. Panamá, en 1885, podía bien dar cuenta de lo que era el inicio de "una larga historia de política de injerencia de carácter imperial". Intereses similares empujaron a Panamá a separarse de Colombia en esa misma década y favorecerán también la consolidación de multinacionales de fuerte capital estadounidense en el rubro agroalimentario, en esa parte de Latinoamérica, primero y en el de las comunicaciones (ferrocarriles, barcos, radiotelegrafia) inmediatamente después.

Por otra parte, todos los adelantos tecnológicos y la interdependencia económica que generaron favorecieron el surgimiento de organismos reguladores como la Unión Radiotelegráfica Internacional, la Unión Postal Universal y la Sociedad de las Naciones. Se multiplicaron reuniones como la Conferencia Postal Internacional (1874) o la Conferencia Internacional de Ferrocarriles (1882). La comunicación de masas comienza a dar sus primeros pasos con la consolidación de las agencias de prensa, gracias al empleo de las entonces nuevas redes de comunicación.

Agencias de prensa de tanta antigüedad como la Havas en Francia (1835), la Wolff en Alemania (1849), la Reuter en Gran Bretaña (1851) y la Associated Press en Estados Unidos (1848) se reparten el mercado mundial. La AP no se incorporará a esta dinámica sino hasta principios del siglo $\mathrm{XX}$, pero lo hará con tanta fuerza (sobre todo en la tercera década de esta centuria) junto con la United Press que cambiará el panorama que habían dominado hasta entonces las agencias europeas.

En la lucha por llegar a las masas, los periódicos se enfrascan en una competencia, en donde el gran triunfador es el periodismo popular, gracias al folletín. La industria del comic también aparecerá a fines del XIX y se con- 
solidará, de manera muy discutible, con el King Feature Syndicate. Pero es la industria cinematográfica la que decidirá la internacionalización de la cultura de masas.

La rivalidad entre los sistemas de los Lumiére y de Edison, entre las productoras Pathé y Gaumont, y el surgimiento de Hollywood (fundada por productores independientes entre 1909 y 1913) signaron los primeros años de esta industria que será un elemento decisivo en la conformación del imaginario mundial, y una herramienta formidable de propaganda ideológica después.

Hasta antes de la Primera Guerra Mundial, no podemos hablar propiamente de un conflicto total, en donde hubiera elementos igual o más importantes que las propias armas. Es ya un tópico hablar del papel que desempeñó la propaganda en ella, debido a que cobró una importancia inusual el lograr la adhesión de las comunidades para cada causa particular. Así, la propaganda se convierte tanto en una técnica de gestión de la opinión de masas como medio de presión sobre los responsables de los gobiernos extranjeros.

La importancia de la destrucción psicológica de los ejércitos antes de los combates efectivos de la Segunda Guerra Mundial condujo a Washington a encargar "a seis compañías privadas -entre las que figuraban las grandes redes NBC y CBS- la producción de programas de radio con vistas a su transmisión hacia el extranjero. y prioritariamente para América Latina." Fue en ese momento cuando cobró conciencia de la necesidad de una política conjunta entre el sector privado y el gubernamental de radiodifusión, pues hasta ese momento (fines de los treintas), sólo había una radio gubernamental: Voice of America.

Por su parte, las potencias del eje ya habían tomado la delantera con emisiones en onda corta en inglés y alemán con destino a EUA, árabe hacia África y el Cercano Oriente, inglés y japonés hacia Hawai y la costa oeste de EUA, hacia China y norte de India.

Fue la Guerra Civil española la que llamó la atención sobre la relevancia de este medio de comunicación, pues ambos frentes, por ejemplo, emitían en árabe para poner a los moros de su parte; los nacionalistas desde Tetuán, los republicanos desde Valencia. Desde aquí también se emitía en francés y ruso para los combatientes de las Brigadas Internacionales.

Los pioneros, sin embargo, fueron los soviéticos, pues desde 1922 disponían de la estación emisora más potente del mundo; transmitía en neerlandés, francés, inglés y alemán. Incluso, "antes de que estallara el segundo conflicto mundial, la Unión Soviética emitía en más de diez lenguas y multitud de dialectos". En esa época, por su lado, Alemania ya había superado la potencia de 
emisión. Mediante la creación del Komintern, el gobierno soviético trató de erigir una "estructura centralizada mundial" que pronto se convirtió en "un fantástico instrumento de comunicación internacional”.

En vísperas de la conflagración mundial, Alemania e Inglaterra contaban con más de 120 receptores por cada mil habitantes; Francia con 77, e Italia no pasaba de 15. Los Estados Unidos se habian distanciado: cerca de 200 receptores por cada mil habitantes. El subequipamiento de los ciudadanos soviéticos era, en cambio, indiscutible: 27 aparatos por cada mil habitantes. Subequipamiento que no lograba paliar la escuch a colectiva del receptor con hilo conectado con altavoces, promovido por las autoridades con la expresa finalidad de controlar mejor sus audiencias (Mattelart, 1993: 105)

Los Estados se enfrentan, desde los orígenes de la radiodifusión, con un triple problema: el reparto del espectro de frecuencias; la amenaza de agresión exterior; la organización de los intercambios de programas. Hasta antes de la $2 \mathrm{a}$. guerra mundial a través de congresos y reuniones internacionales, se había acordado la necesidad de poner la radio al servicio de la paz. La realidad, sin embargo, era otra, y la única posibilidad de defensa ante la agresión internacional que significaba la propaganda radiofónica fue la interferencia.

La preocupación del gobierno de EUA era la posibilidad de una adhesión de los múltiples descendientes alemanes que poblaban sus territorios y los latinoamericanos (600 mil en Brasil, 150 mil en Argentina) al gobierno del III Reich. Esto era una aspiración real de Berlín, quienes contaban con una población de 14 millones de personas en colonias alemanas en el extranjero. "Así pues, a partir de la amenaza que representaba este frente cultural abierto en América Latina por los nazis, el gobierno de Washington se vio obligado, por primera vez, a pensar en una estrategia en el marco más amplio de sus objetivos geopolíticos." Se tomaron muchas acciones al respecto:

- Acercamiento, a través de las relaciones públicas, a los países latinoamericanos.

- crear una división de relaciones culturales dentro de Departamento de Estado para trabajar con ellos.

- Ediciones en castellano del Reader's Digest y labor en ese sentido por parte de Time.

- Eliminación de temas o personajes del cine de Hollywood que pudieran herir la susceptibilidad latinoamericana.

- Aparición de figuras latinoamericanas en las películas de Disney.

- Episodios al respecto en los comics.

- Labor activa de los clubes Rotarios y de Leones (Rotary y Lions).

- Financiación de programas radiofónicos en español y portugués. 
- Exportación masiva de capitales para invertir en dichos países (en una década pasó del 6,3 al 35\%). Esto durará cerca de veinte años, hasta que en los cincuenta fijen sus ojos en Europa.

- Relaciones militares privilegiadas para constituir un sistema multilateral de defensa: misiones militares en Colombia (1938) que se añadirán a las ya existentes del Caribe y Panamá.

Así, cultura, ideología e información se vinculan estrechamente con las acciones militares.

\section{Guerra y Comunicación}

En los años de la Segunda Guerra Mundial, el término "propaganda” fue desplazado por el de "guerra psicológica”. Éste estuvo mucho en boga por el interés de los psicólogos de demostrar la eficacia de sus teorías. Los británicos usaron el vocablo "guerra política". "Ambos términos designan esta forma de operaciones de información (Intelligence) que recurren a las ideas para influir en las políticas. Se refieren a opiniones, y a comunicaciones con los otros. Es una persuasión organizada mediante recursos no violentos". Aún así, hubo y hay muchas polémicas sobre las diferencias entre guerra psicológica e información, propaganda e información, persuasión y comunicación. A 10 que a nadie le queda duda es que la Segunda Guerra Mundial fue el primer laboratorio de tamaño natural de la moderna sociología de la comunicación de masas.

Para llevar su propaganda exterior, EUA modifica los organismos con que ya contaba y surge así la OWI (Office of war information) y la OSS (Office of Strategic Services). La diferencia entre ambas era que la primera se responsabilizaba de la propaganda manifiesta, mientras que la segunda de las operaciones clandestinas. Sociólogos y psicólogos trabajaron en ambos así como en la Voice of America.

La postguerra fue el espacio donde se publicaron muchos textos que analizaban las estrategias de propaganda empleadas. La antropología, por ejemplo, sirvió en la guerra psicológica, al instrumentar una estrategia que socavaba la moral de las tropas, pero que preservaba una continuidad dentro de la organización social con el fin de velar por una transición cultural.

Se demostró que la propaganda sirve de muy poco, mientras que los grupos primarios (de amigos, por ejemplos) permanezcan intactos. Así, el mensaje persuasivo era aquel "cuyas propiedades son capaces de alterar el funcionamiento psicológico del individuo y de inducirle a realizar actos deseados por el emisor". 
Fue ésta también la época donde se iniciaron las investigaciones sobre la comunicación internacional y el interés por la propaganda en onda corta. Esto sólo fue el inicio de otra guerra que duraría cuarenta años: la del Este con el Oeste.

La OSS se convirtió en CIA y la OWI en Office of Internacional Information. Esta, años más tarde, fue desmantelada en los setenta por cuestiones políticas. La disposición con que se creó la CIA "Legitimaba las instituciones del tiempo de guerra e instauraba sus prioridades como las del estado de paz. Pero, sobre todo, proporcionaba el marco legal para mantener la movilización excepcional de la guerra”. De la inmediata postguerra se pasa a un periodo de crecimiento enorme (11 por ciento) y un abatimiento del desempleo (del 6 al 3\%). Con esta acta se "sellaba la alianza permanente de la industria y del estado den pie de guerra”, lo cual dará pie a un gran auge de las industrias aeroespaciales y electrónicas de la comunicación.

De lo anterior surgen alianzas entre el Pentágono y el sector privado, la producción industrial y la militar, la investigación universitaria y la seguridad nacional.

Si en un inicio la investigación sobre la guerra psicológica estuvo sólo en manos de la teoría psicológica y sus métodos de investigación, después se expandió a otros ámbitos, revelando la rivalidad existente entre disciplinas y corrientes, por una parte, y el deseo de captar recursos financieros para las investigaciones, por la otra. Se intentó dar una orientación más civil y menos militar, impulsándose conceptos como "comunicación política" y "comunicación internacional".

Los estudios sociológicos toman la delantera, aunque también se retoman investigaciones del pasado. Por ejemplo, se redescubre la importancia del grupo primario. "Esto hace que perciban el flujo de comunicación como un proceso en dos etapas: donde el rol de los líderes de opinión resulta esencial. Lo cual se convirtió en el two-step-flow (flujo en dos pasos). En el primer escalón se encuentran aquellos que están relativamente bien informados porque están directamente expuestos a los medios; en el segundo, se encuentran aquellos cuyo contacto con los medios es menor y que dependen de los otros para obtener información" (1993: 115). En el primer paso se detecta a los líderes de opinión, quienes mediante canales impersonales transmiten la información a los demás, lo cual es el segundo paso.

Se sustituye el concepto del efecto masificador y se acepta la tesis de Berelson (1949): "ciertos tipos de comunicación referidos a ciertos tipos de problemas, que se dirigen a ciertos tipos de personas que se encuentran en ciertas condiciones, producen un cierto tipo de efectos". Vemos claramente 
dos posturas: una behaviorista (en donde el medio tiene todo el poder) y otra neoliberal (en donde el consumidor tiene una soberanía absoluta).

Múltiples son los discursos explícitos en donde se evidencia la necesidad de que la comunicación internacional estuviera al servicio del mundo libre.

La guerra de Corea propicia afirmaciones del tipo de que es necesario profesionalizar la guerra psicológica, ante la certeza de que el bienestar nacional e internacional está vinculado a las técnicas de la investigación en ciencias sociales.

Las inversiones del Pentágono en la industria de la informática fue un factor determinante para el despegue de éste. La principal empresa que sacó ventaja de ello fue la IBM, gracias a un contrato ganado para desarrollar el primer ordenador de transistores (1959) y comenzar con la teleinformática, al interconectar ordenadores con la línea telefónica de orígenes distintos.

Otro frente de la guerra fría fue la carrera espacial, la cual parecía ser el elemento que decidiera cuál de las potencias le ganaría a la otra. Para la NASA, el que la URSS tomara la delantera significaba que la imagen de la democracia (de EU A) se podría venir abajo ante la opinión internacional. Es la época de los viajes a la Luna (1961), de los satélites artificiales (1957), de la unión de los continentes vía el satélite Telstar, el surgimiento de Comsat para explotar la tecnología espacial (cuatro grandes compañías se hicieron con la mayoría de las acciones: ATT, ITT, GTE y RCA). La influencia de EUA, a través de Intelsat, es absoluta dentro de la red internacional de comunicaciones por satélite. Frente a ello, la URSS sólo puede oponer una tímida resistencia a través del Intersputnik.

Al entibiarse la guerra fría, decayó el interés por la carrera espacial y se le dio un giro a las investigaciones: del punto de vista militar a uno más pragmático, más civil; los satélites se ponen al servicio de la comunidad: satélites de comunicación, de observación meteorológica, observación de los recursos naturales, etc. La industria electrónica y aeroespacial busca diversificar su oferta y para dejar de ofrecérsela únicamente a la defensa militar.

Es el principio de los años sesenta en donde la educación y la pedagogía se convierten en un mercado portador: surgen las series educativas de televisión, la reinvidicación de las minorías negras e hispanohablantes.

Otros problemas sobre la comunicación internacional fueron estudiados por Edward Hall, representante de la Escuela de Palo Alto, a través de la proxémica y la comunicación intercultural. Hace hincapié en la necesidad de entender los códigos culturales, en los que los lenguajes del espacio, del tiempo, de las posesiones materiales, etc. son distintos para cada cultura. De esta comprensión depende, por ejemplo, el éxito de los negocios con otros países. Se 
pone en entredicho la teoría matemática de la información (modelo lineal de comunicación) al oponer un modelo múltiple de varios niveles y contextos.

En la década de los ochenta se legitima el enfoque multicultural, al incrementarse las relaciones entre las distintas culturas y al decaer la hegemonía de EVA. En este país comienzan a caer en la cuenta de su enorme egocentrismo (al ignorar a los Otros), lo cual ha contribuido a dicha decadencia.

EUA tiene que cuestionar sus conceptos sobre la guerra psicológica con las llamadas "guerras de minoría" de finales de los años sesenta. Estas guerras se oponen al Estado regular y surgen en el contexto de la amenaza nuclear, el enfrentamiento indirecto entre superpotencias y el gran movimiento de descolonización. La guerra popular supone otra relación orgánica con el pueblo, con la masa, y hay también otra actitud de la prensa, más crítica, con respecto de las decisiones militares.

Quizás un poco tarde, el gobierno estadounidense comprendió la importancia de escuchar al adversario para combatirlo mejor. Si el apoyo de la población es vital para estas guerras, hay que estudiar a la población (sus tensiones internas, sus contradicciones económicas, políticas, culturales y sociales).

La diferencia entre esta guerra de minorías y otras es no sólo la amplitud de sus acciones sino también la indefinición del enemigo. El Pentágono lo enfrentará mediante la "pacificación", mediante el control de las poblaciones, vía diversos elementos: El primero, la acción psicológica (edición de periódicos, octavillas, altavoces, cuerpos paramilitares, intervención social (construcción de escuelas, dispensarios, etc.) y restricción en la compra de receptores de radio. El segundo, traslados de la población y realojamientos. El tercero, obtención del "informe", información obtenida mediante interrogatorios y "brutalidades inevitables". A través de éstas no sólo se obtiene información sobre las redes clandestinas enemigas, sino también se destruye en los apresados el sentido de solidaridad con una organización y una colectividad.

Sobre la guerra contra-insurgente teorizarán tanto los franceses como los ingleses, pero también los latinoamericanos (especialmente los brasileños). Éstos elaboraron un estudio sobre la relación televisión-violencia-política, en el que se concluye que la subversión ha impregnado no sólo los reportajes sino también las representaciones de la ficción. El control y la presión del Estado desembocan en que los programas "abiertos" se emiten con mucha menor frecuencia que los "cerrados" y alcanzan menores audiencias.

Los teóricos brasileños evidencian la tensión que se introduce, en los regímenes dictatoriales, entre las normas de la guerra psicológica contra el enemigo interior y la cultura comercial de masas. Todo ciudadano se convierte en un sospechoso en potencia. 
Otro de los cambios, en esta guerra de minorías es que si anteriormente los militares reclamaban un papel protagónico, ahora, el Pentágono comprende que son las instituciones y las tradiciones son las que deben atacar a la subversión. Dos elementos favorecen esta visión: la existencia de una marco institucional de colaboración político militar (gracias a la misma ley que autorizó el surgimiento de la CIA, la National Security Act) e investigadores dispuestos a estudiar los objetivos de estas luchas.

La guerra de Vietnam enfatiza la excesiva confianza que se había depositado en los expertos en guerra convencional, aunque intelectuales del MIT y del Instituto Smithsoniano lo habían advertido, y habían propuesto, en cambio, un enfoque pluridisciplinar para "formular modelos de análisis del cambio social y del control social en los países subdesarrollados".

Años después se tejen redes de investigación entre empresas privadas y centros universitarios para estudiar a las minorías étnicas y religiosas, sus valores, su vulnerabilidad, etc. No toda la comunidad universitaria se mostró conforme con esta alianza entre centros de investigación y el Pentágono y sus institutos, aduciendo que así se estaban formando mercenarios de la ciencia, seducidos por las becas, subvenciones y apoyos financieros.

Paralelamente a ello, fue creciendo la diferencia entre los distintos actores políticos en la escena de EUA. Los medios nacionales se habían convertido ya en una nueva fuente de poder: grandes cadenas de televisión, de revistas y periódicos como el Washington Post y el New York Times. Se llegó, incluso, a la conclusión, que la televisión contribuía a minar la autoridad gubernamental, al ser una agencia despatriante.

Han sido muy pocas las voces que se han levantado, desde el seno mismo del gobierno de EUA, para denunciar cómo las actividades de propaganda del Departamento de Defensa han influido en el modo de pensar de los ciudadanos de ese país. Una de ellas fue la del senador William F. Fullbright, en cuyo informe desmenuza el desproporcionado desarrollo de las estrategias de información del poder militar.

La Agencia de Información de EUA tenía como misión influir en las naciones extranjeras en su forma de considerar a EUA, a través de la utilización "sin disimulo, de numerosas técnicas de comunicación contactos personales, red radiofónica, bibliotecas, publicación y distribución de libros, prensa, televisión, cine, exposiciones, enseñanza de inglés, etc", y siempre enterando de sus actividades al gobierno y sus representantes. Lo que Fullbright revela en su informe, en 1972, es que muchas de estas actividades se realizaron clandestinamente, por una parte, por la otra, la relación entre el organismo público y las grandes empresas norteamericanas, y el propiciamiento de la confusión entre propaganda e información. 
Otra comisión senatorial, la de Frank Church, revelaría en 1976 operaciones secretas entre la CIA y el Pentágono en cuanto a propaganda, guerra económica, sabotajes y antisabotajes, ayuda a la guerrilla o a movimientos de oposición, etc. Este sería el tipo de black propaganda que se efectúa sigilosamente: no identifica sus fuentes reales, insinúa que la información proviene del mismo enemigo, difunde y fabrica informaciones y rumores.

Church subrayó la capacidad de los medios, debido a dichas operaciones clandestinas, de manipular y engañar al público de los propios EUA, y dañar a la prensa libre en su credibilidad e independencia. Tales operaciones fueron detectadas sobre todo en Chile (la caída del presidente Allende, en 1970), pero también en Irán, Guatemala, Grecia, Italia, etc., consideradas zonas de subversión real o en potencia. Fuera de estas denuncias, el común denominador ha sido la indiferencia.

Sobre las actividades en la URSS fue posible enterarse debido a la deserción de antiguos responsables de sus servicios secretos. La creencia de que las actividades clandestinas de EUA eran mucho mayores que las de la URSS se vinieron abajo: las actividades de éstos equivalían a seis veces más que la de aquéllos. Esto en cuanto a la cantidad, el problema es que las actividades de la URSS eran explícitamente propagandistas, por lo que su eficacia era prácticamente nula.

Revisión de correspondencia, intercepción de trabajos académicos, censura de publicaciones eran algunas de las acciones más frecuentes. Quien emitiera ideas u opiniones era susceptible de verse como integrante de algún complot de origen burgués. Así, en los estudios sobre la comunicación en la URSS, en ese periodo, se llegó a la conclusión que ahí "la información no es más que una parte de las campañas de propaganda del partido". La impotencia de poder llegar al ciudadano medio se evidenció con la caída de los regímenes comunistas.

Por su parte, George Bush, a raíz del término de la guerra fría y la guerra del golfo, decidió estudiar la reorganización de las radios y las televisiones oficiales de EUA, a fin de impulsar su competitividad. Ésta no se demostró durante la invasión de Panamá, en donde la cadena privada CNN señaló un ascenso enorme y demostró como la inmediatez de las imágenes pueden influir, incluso, en la modificación de las decisiones de los políticos.

La CIA atravesó el peor periodo de crisis con el descubrimiento del Irangate (malversación de fondos, sacados de la venta de armas a Irán para darle el dinero a la contra nicaragüense). El que la CIA tampoco haya previsto la caída del muro de Berlín ni el golpe de estado en la URSS en 1991 demostró una excesiva confianza en los métodos de espionaje electrónicos, pero un ineficaz 
manejo de sus recursos humanos, falta de visión para interpretar el cúmulo de datos que manejaban y una visión maniquea del bien y del mal que ya no funciona en una sociedad en donde no está nunca claro quién es el enemigo.

La delantera la han tomado los japoneses, en su comprensión de la importancia de la vigilancia tecnológica por encima de otros espionajes: del procesamiento de datos sobre las estrategias industriales de las potencias competidoras y la intervención de especialistas pertenecientes a diversas culturas.

La Guerra del Golfo es considerada como una guerra de la comunicación por dos razones: por el lugar que ocupa la información, censurada por un sistema de pools (pequeños equipos de prensa), bajo estricto control militar. Esto resaltó no sólo una manipulación en lo que se podía ver, a quiénes se podía entrevistar, sino el trato desigual, dependiendo del medio que se tratara. La televisión se convirtió así más en un seguidor que en un líder de opinión.

La guerra de la información "es la heredera de las técnicas de la guerra psicológica acumuladas en el transcurso de las guerras anteriores": llamamientos a la deserción, operaciones de desinformación, de producción de falsas noticias o de rumores sobre el potencial del ejército enemigo; la novedad en esta ocasión radicó en la connivencia de periodistas en esta labor.

El cambio cualitativo en esta guerra, sin embargo, es "la forma en que se han introducido en el imaginario de la cultura de masas". Hablamos de una estética de las armas, que de acuerdo a cómo sean presentadas en los distintos programas de televisión, serán cada vez más aceptadas y familiares para el público.

La segunda razón por la que ésta fue una guerra de comunicación fue la puesta en imagen del triunfo de los armamentos inteligentes (misiles pilotados por sus propios ordenadores, por ejemplo). La guerra en el Golfo fue como una fábrica japonesa, en donde sólo se generaban las piezas necesarias, bajo pedido, con un número muy bajo de combatientes reales (el 95\% de las operaciones logísticas de la fuerza aérea fue sin intervención humana, por ejemplo). El análisis de esto, se cree, podrá cambiar la organización del trabajo en el mundo industrial del mañana.

La guerra, entonces, ha cambiado: la informática y la comunicación, y la automatización de la maquinaria guerrera sustituyen los conceptos militares tradicionales. El que ya no se tenga que ver la cara del enemigo y pueda matársele a distancia propiciará guerras en la que los expertos y la asepsia serán fundamentales.

Sin embargo, "la lógica de la guerra ha hecho florecer los pensamientos simplificadores, las intolerancias y las certezas ciegas en la representación mediática”. El gran peligro es que este triunfalismo ahonde el abismo imaginario y cultural entre los excluidos y los integrados. 


\section{Cultura y Comunicación}

La reglamentación internacional de los flujos comunicativos ha suscitado controversias, guiadas por los intereses de los países hegemónicos. En todos los casos, dos ideas se enfrentan: la libre de circulación de la información contra el principio de soberanía nacional. La Guerra Fría no simplificó esta contraposición, ya que tanto los países del Este como del Oeste ejemplificaban dos modos distintos de organización de la información (la saturación, la supuesta transparencia de éstos, y la concepción del ocio como entretenimiento; la discreción absoluta de los primeros y su democratización del ocio, mediante al acceso a la alta cultura).

Así, mientras los Estados Unidos abogaban por la libre circulación de la información (incluyendo la recepción de datos vía satélite de los recursos naturales de los países, sin tener que solicitar el consentimiento de éstos, y con la ventaja de que concentraban ya el $65 \%$ del flujo mundial de la información), otros países como Francia comenzaban a cuestionar la propuesta. A este panorama se suma el surgimiento de nuevos focos críticos en los países del Sur. Con los ojos puestos en el Norte, estas naciones estimaban que su propia herencia cultural era el principal obstáculo para evolucionar social y económicamente.

Con un modelo audiovisual semejante al de los EUA, América Latina internacionalizaba su programación, cuando en Europa todavía prevalecía el modelo de monopolio público. En Venezuela, Argentina y Chile comenzaron a efectuarse estudios sobre áreas diversas de la televisión; y México y Brasil se convertirán en potencias audiovisuales en Latinoamérica. Sin embargo, la dependencia de estos países a sus relaciones con EVA sienta las bases para que podamos hablar de una auténtica recolonización del tercer mundo.

La mutación del orden mundial ha sido marcado, según Mattelart, por dos sucesos: la desaparición del llamado bloque socialista y la Guerra del Golfo. El primero pone fin a una concepción de internacionalismo (con todo lo que esto implicó, sobre todo en el periodo de la Guerra Fría) y el segundo registra una hegemonía mundial, en donde las utopías se declaran en retirada, la ideología del progreso se ve francamente desgastada y un nuevo modo de organización mundial: la geoeconomía cede su lugar a la geopolítica.

Lo anterior es transparente si analizamos cómo se ha ido decantando la significación del término "globalización". Mercado de capitales, productos y servicios, dirección y técnicas de fabricación convertidos en globales, al mismo tiempo que se evidenciaba una falta de reglamentación en todo ello. Esto traerá como consecuencia un palpable desequilibrio de las fuerzas sociales, 
un cuestionamiento sobre el papel paternalista del Estado y la interrogación si el servicio público no estaría determinado por las necesidades de las empresas.

En consecuencia, los modelos de la comunicación empresarial son irradiados hacia las instituciones gubernamentales, humanitarias y colectivas. Aunque aún en nuestros días está abierta la polémica sobre la conveniencia de que dichas instituciones echen mano de recursos propios del arte y la publicidad, es un hecho que la inclusión de éstos ha repercutido en la comunicación internacional: las estrategias que se fijan no se sedimentan en los viejos órdenes de lo local y lo foráneo, sino en ambos espacios vinculados en un orden simultáneo. Así, se anula la concepción del espacio fijo, inamovible y único. De igual forma se operará en el terreno de la producción y la comercialización, en donde ambos procesos se encuentran tan relacionados, que no hay posibilidad alguna de disociación. Específicamente, en el área de la comunicación, ésta y la tecnología registran un movimiento similar, a merced de la digitalización.

En tanto, ¿qué sucede con el receptor? El abismo que en los hechos se produce entre la libertad de elección de éste, signada por su libertad de expresión, y la libertad de expresión comercial determina el total triunfo de ésta sobre aquélla. Así, la sobada idea de la soberanía de elección del individuo no es más que uno de los tantos casos de desigualdad dentro de los llamados flujos de la comunicación.

En las distintas reuniones convocadas por la UNESCO durante los setenta y principios de los ochenta se abrió un foso entre los ideólogos de la mercancía y los defensores de las identidades culturales. Los primeros esgrimen la necesidad de que el público vea lo que él quiera, en una clara argumentación populista. El problema es que el público no ve lo que quiere, como individuo libre de escoger, sino sólo aprecia la oferta que le ponen ante los ojos que suele ser uniforme y siempre favorecedora a los intereses de las grandes empresas mundiales.

Mientras más énfasis se haga en la libre elección del receptor, más dudas genera esta actitud que vela sobre el interés de que la interpretación de las lecturas de la realidad vaya en consonancia con las culturas hegemónicas. Al fin y al cabo, esto no hace más que reforzar no sólo la enorme desigualdad en la dirección y la cantidad del flujo de la información, sino también legitima la subordinación cultural de los pueblos y las culturas más dependientes. La escasez de foros para plantear esta problemática propicia la imposición de todas las ideas que giran hacia la ficción de la globalización y el equilibrio dentro de la comunicación internacional.

La brecha que se abrió desde principios de siglo entre los que ahora conocemos como países del primer y el tercer mundo no ha podido ser acor- 
tada, en casi un siglo de intentos. Ya en 1919, la Sociedad de Naciones dio a conocer un texto en el que aseguraba que el mejor método para desarrollar a los pueblos que eran "incapaces aún de administrarse por ellos mismos", era confiándolos en "tutela" a las naciones desarrolladas". Si la terminología ya aparecía desde ese momento, a fines de los años cuarenta se difunde debido a la tesis de presidente de Estados Unidos, Harry S. Truman. Éste postula la necesidad de frenar los grandes desequilibrios económicos, dado que éstos podían favorecer el paso del comunismo entre los países menos desarrollados.

Los años sesenta serán testigos del ir y venir de múltiples teorías, entre las que prevalecerá la idea de la importancia de la modernización de las sociedades tradicionales, resistentes a un cambio cultural. La sociedad moderna, en cambio, está en, continuo cambio, regida por criterios de eficacia y racionalidad. Esta es también la época en la que la comunicación y específicamente los medios, Son vistos como agentes de desarrollo y productores de conductas modernas.

Para "construir" esas naciones que requerían de los modelos de progreso de otras, el Pentágono vio en las dictaduras militares una plataforma. Plataforma que, por una parte, frenaba la posibilidad de la expansión comunista, del triunfo de los brotes insurgentes y aseguraba un proceso más fácil, unos países más dóciles y aptos para alcanzar el desarrollo.

La explosión demográfica, la innovación en el campo y las nuevas tecnologías educativas se convirtieron en la punta de lanza del proyecto de modernización propuesto para América Latina, especialmente, y a los países del tercer mundo, en general. La comunicación desempeñó un papel de gran importancia, sobre todo en el caso de las campañas para frenar la explosión demográfica de esos países.

Todas estas tesis y planes para el desarrollo comenzaron a decaer casi dos décadas después, una vez que se divulgaron estudios en lo que se sacaba en claro es que no habían hecho sino desequilibrar aún más las estructuras sociales de los países en vías de desarrollo. Este es el momento en que surgen dos planteamientos antagónicos: el que se refiere a las nociones de co-desarrollo (a través de las cuales se buscan nuevas formas de relación entre los países del Norte y el Sur) y el de la posibilidad de que los países del tercer mundo se desconecten de los países hegemónicos, se disocien del sistema- mundo.

El aparato conceptual con el que finaliza Mattelart su texto lo condensa en la idea que da título a su libro: la comunicación-mundo. El objetivo no es mitificar la supuesta igualdad que trae consigo el término "globalización". Por el contrario, hace ver que la mundialización de las economías y los sistemas 
de comunicación va ligada a reforzar y generar nuevas desigualdades entre los distintos grupos sociales.

Pensemos en la gran búsqueda de los ochenta por encontrar los universales culturales que, lejos de acercar a los pueblos, perseguían encontrar fórmulas cuasimágicas de penetración comercial, con el menor esfuerzo posible. Las culturas, por su parte, no han tardado en reaccionar revelándose como singulares e insustituibles, en un movimiento centrífugo a las propuestas aceptadas como cosmopolitas.

En La comunicación-mundo, Armand Mattelart sintetiza lo que en distintos textos se encontraba germinalmente; en esta obra expone los desafíos que ha tenido la comunicación internacional a partir del siglo pasado, principalmente, desde una perspectiva cultural. Mientras que ésta no sea tomada en cuenta, como memoria colectiva, difícilmente podrá ser objeto de racionalización. Adoptando las tres dimensiones de la cultura que propone Jürgen Habermas (lenguaje, trabajo y poder), el autor advierte sobre los peligros de encerrarse en un localismo, pero también en sobredimensionar el ámbito internacional.

La necesidad de que la historia no se olvide, en el campo de la comunicación, es una de las principales preocupaciones que se traslucen en este texto. De aquí que se le haya adjudicado, en ciclos más o menos regulares, funciones mesiánicas dentro de los ámbitos más dispares y diversos. No obstante, reconoce este investigador que la comunicación "se ha vuelto demasiado importante para el porvenir de las relaciones entre las culturas, como para poder seguir retrasando su reapropiación por parte de la ciudadanía.

¿Es posible, se pregunta Mattelart, escribir una historia de lo internacional sin una perspectiva etnocentrista o una colonizada? La respuesta no la tiene, pero es necesario formularla sobre todo en esta década en donde el concepto de la nacional varía en sus significados políticos y culturales.

\section{Bibliografía}

Mattelart, Armand, 1976: Multinacionales y sistemas de comunicación, México: Siglo XXI.

Mattelart, Armand, 1993: La comunicación--mundo. Historia de las ideas y de las estrategias, Madrid: Fundesco.

Mattelart, Armand y Michele Mattelart, 1993: Pensar los medios. Madrid: Fundesco.

Mattelart, Armand, 1994: Los nuevos escenarios de la comunicación internacional, Barcelona: Centre d'investigació de la Comunicación. 